\title{
The Therapeutic Potential of Cocos nucifera Water on Cadmium-Induced Lipid Toxicity in Male Rat
}

\author{
Olabisi O. Ogunrinola ${ }^{1 *}$, Omolade 0. Fajana ${ }^{1}$, Babakunle 0. Williams ${ }^{1}$, Eunice Ogedengbe ${ }^{1}$, Ajibola A. \\ Onifade $^{1}$, Francisca C. Ekeocha ${ }^{1}$ and Kareemat 0. Shasore ${ }^{1}$ \\ ${ }^{1}$ Cell and Tissue Culture Research Lab. (Drug Discovery Unit), Department of Biochemistry, Lagos State University, Ojo - Lagos, Nigeria
}

\begin{abstract}
Received: 7 November, 2016; Accepted: 25 November, 2016 ; Published: 5 December, 2016
*Corresponding author: Olabisi O. Ogunrinola, Cell \& Tissue Culture/Drug Research Lab, Biochemistry Department, Lagos State University, Ojo Lagos, Nigeria, Tel: +234 803320 4476; E-mail: ooogunrinola@yahoo.com
\end{abstract}

\begin{abstract}
Cocos nucifera (Coconut) water is one of the world natural products with increasing scientific evidence that support its role in health and medicinal application. This study was undertaken to investigate the therapeutic potential of Cocos nucifera water on cadmium-induced toxicity in male rat. Sixty-four animals were randomly grouped into five, groups $3,4,5(n=16)$ were exposed to 100,200 , and 300 ppm cadmium doses for 6 weeks in their drinking water as cadmium chloride. At the end of 6 weeks, eight from each group were sacrificed and the remaining was administered with 10 $\%$ coconut water for a week. Control animals ( $\mathrm{n}=8$; group 1 ) received distilled water and Cocos nucifera water (n=8; group 2) for the same six week period. Lipid profile analysis revealed that cadmiuminduction exhibited different dyslipidemia patterns. Significant dose-dependent hypocholesterolemia, hypotriacylglyceridemia and hypophospholipidemia characterized the effect of cadmium exposure at all doses while Cocos nucifera water treatment for a week reverse these effects by 4,24 and $22 \%$ in plasma and 16,15 and $2 \%$ in the erythrocytes respectively. The exposure to cadmium resulted in reduced cholesterol, triacylglyceride concentration in the brain and cholesterol, phospholipids concentrations in the hepatic compartments. Also, the exposure caused an increase in brain phospholipids and hepatic triacylglycerides concentrations. The administration of Cocos nucifera water significantly $(p<0.05)$ reverses these effects. Our findings indicate that although the cadmium-exposure at different doses resulted in down and upregulation of lipid profile, the administration of Cocos nucifera water was able to reverse the damage caused by cadmium-induced toxicity.
\end{abstract}

Keywords: Cadmium; Cocos nucifera water; Lipid profile; Brain; Therapeutic; Dyslipidaemia

\section{Introduction}

The Cocos nucifera (Coconut) plant has long been recognized as a valuable source of various commodities for human life. The water of the endosperm, known as coconut water, is the most nutritious, wholesome beverage that the nature has provided for the people to fight the sultry heat and other therapeutic purposes [1]. In recent years, coconut water has also assumed great nutritional significance owing to its physio-chemical nature. It satisfies thirst and as well invigorates the body and brings about a sense of wellbeing and renewed health [2]. Coconut water has been used as an oral rehydration in patients with diarrhoea to replace fluid loss from the gastrointestinal tract, as a home glucose electrolyte solution for well-nourished children with mild diarrhoea and in an extreme situation such as short-term intravenous hydration fluid in a patient $[3,4]$.

Research has shown that coconut water contains a variety of nutrients like vitamins, antioxidants, amino acids, enzymes and growth factors. Also, as a good source of the major minerals like calcium, magnesium, and potassium and some trace elements like zinc, selenium, iodine, manganese, boron, and molybdenum [5]. Its nutritive properties are widely recognized to be an electrolyte, antidote, anti-oxidant, cardio-protective, hepatoprotective, anti-thrombotic, anticancer, anti-cholecystitic, anti-bacterial, anti-caries, antiprotozoal, antiviral, anti-diabetic, immune-stimulatory and anti-atherosclerosis activities [6]. Some of the diseases which the coconut ameliorates or reverse might have been generated from the accumulation of heavy metals.

Heavy metals are also considered as trace elements because of their presence in trace concentrations (Parts per Billion (ppb) ranges to less than $10 \mathrm{ppm}$ ) in various environmental matrices. Cadmium (Cd) is one of the most toxic heavy metals present in the environment and has been involved in poisoning cases of human and animal population, thus becoming a serious threat to living organisms [7]. Some regulations and recommendations doses for cadmium include $0.04 \mathrm{mg} / \mathrm{L}$ in drinking water (Environmental Protection Agency), $0.005 \mathrm{mg} / \mathrm{L}$ in bottled water (Food and Drug Administration). These regulations and recommendations can be expressed as "not-to-exceed" levels [8]. The exposure to cadmium dose that is higher than recommended doses causes various forms of diseases such as osteomalacia and osteoporosis, hypertension, arteriosclerosis, anaemia and cancer $[9,10]$; inhibit the activities of various pancreatic proteases [11] and antioxidant enzymes which release free oxygen radicals [10].

Cadmium stimulates the formation of metallothioneins (a family of low molecular weight metal binding proteins unique 
in their high cysteine content) and reactive oxygen species, thus causing oxidative damage resulting in loss of membrane functions, causing dyslipidemia $[12,13]$. Earlier research conducted in our laboratory reported the changes in the plasma, erythrocyte, brain and hepatic cell lipid profile of rat after low-level exposure to cadmium through drinking water [13]. The therapeutic benefits of plant foods have been the focus of many extensive dietary studies. This prompted the present study to continue our efforts to investigate the therapeutic effect of coconut water on low-level cadmium-induced toxicity in the rat.

\section{Materials and Methods}

\section{Chemicals}

Cadmium chloride was procured from Sigma-Aldrich, Missouri, USA. All other chemicals used in this study were of the purest grade available and were obtained from the British Drug House (BDH) Chemicals Limited, Poole, Dodset, England.

\section{Preparation of coconut water}

Matured peeled coconut was purchased from the Badagry Central market, Badagry Local Government, Lagos, Nigeria, botanically authenticated by the Department of Botany, Lagos State University, Ojo-Lagos. They were cut open at the 'eye' of the coconut to extract the water every day of the research. $10 \%$ of the collected coconut water was then administered to the animals daily.

\section{Animals and treatment}

Sixty-four (64) male Wistar albino rats with a mean weight of $190 \mathrm{~g}$ bred in the Animal House of the Department of Biochemistry; Faculty of Sciences; Lagos State University, OjoLagos, Nigeria was used for the experiment. They were housed in animal stainless cages with a $12 \mathrm{~h}$ light / dark cycle and allow free access to food and water for 14 days prior to the experiment.

They were randomly and equally distributed into eight groups with eight rats in each group. The cadmium doses were selected based on the research of Yapping et al [14]. Distilled water was administered to the control group because its demineralized water and coconut water which consists of minerals was given to the positive control animals.

Group 1: Given distilled water for 6 weeks (Control).

Group 2: Given $10 \%$ coconut water and feed for 6 weeks (Positive control).

Group 3a: Administered 100 ppm $\mathrm{Cd}$ as cadmium chloride for 6 weeks.

Group 3b: Administered $100 \mathrm{ppm} \mathrm{Cd}$ as cadmium chloride for 6 weeks and $10 \%$ coconut water for 1 week.

Group 4a: Administered 200 ppm Cd as cadmium chloride for 6 weeks.

Group 4b: Administered 200 ppm Cd as cadmium chloride for 6 weeks and $10 \%$ coconut water for 1 week.
Group 5a: Administered $300 \mathrm{ppm} \mathrm{Cd}$ as cadmium chloride for 6 weeks.

Group 5b: Administered $300 \mathrm{pm} \mathrm{Cd}$ as cadmium chloride for 6 weeks and $10 \%$ coconut water for 1 week.

All groups were fed ad libitum with grower mash (product of Animal care, Lagos, Nigeria). At the end of the treatment period, the rats were weighed and sacrificed under light ether anesthesia. The blood was collected, centrifuge into plasma was collected while the brain was quickly excised, weighed and placed on ice until required for biochemical analysis. All experiments on the rats were approved by the Animal Ethical Committee of the Department of Biochemistry, Lagos State University, Ojo-Lagos, Nigeria, in compliance with the Ethical guide for the care and use of laboratory animals (NIH Publication No. 85-93, revised 1985) [15].

\section{Plasma and erythrocyte lipid profile}

Plasma concentrations of total cholesterol and triglycerides were determined with commercial kits (Spin React S.A., Santa Colona, Sant Esteve De Bas, and Spain). Phospholipids in plasma were extracted with chloroform-methanol mixture $(2: 1, \mathrm{v} / \mathrm{v})$ as described by Folch et al [16] and the extraction of lipids from erythrocytes was done using chloroform-isopropanol 7:11 $\mathrm{v} / \mathrm{v}$ method [17]. The extracts were stored at $-20^{\circ} \mathrm{C}$ for further analysis. Determination of lipids was performed as described by Stewart [18]. Briefly, $100 \mu \mathrm{l}$ of lipid extracts as well as 100 $\mu \mathrm{l}$ of chloroform were evaporated to dryness over a hot water bath at $60 \mathrm{oC}$ and allowed to cool. $2.0 \mathrm{ml}$ chloroform and $2.0 \mathrm{ml}$ of ammonium ferrothiocyanate were added, vortexed and allow the phases to separate. The chloroform layer was removed and the absorbance read at $488 \mathrm{~nm}$ against blank using UV/ Visible Spectrophotometer (Model SM 755s), a product of Surgien field Instrument, Zhejiang, China (Mainland).

\section{Brain and liver lipid profile}

Lipids were extracted from the brain and liver as described by Folch et al [16]. $10 \%$ brain and liver homogenate was prepared with chloroform-methanol mixture $(2: 1, \mathrm{v} / \mathrm{v})$, washed with $0.05 \mathrm{M}$ $\mathrm{KCl}$ solution. An aliquot of the chloroform-methanol extracts was then used for the determination of cholesterol, triglyceride and phospholipid concentrations. Cholesterol was determined as described by Allain et al [19], triacylglyceride concentrations determined to follow the procedure described by Kriketos et al [20] while determination of phospholipids followed the same procedure as described for plasma.

\section{Statistical analysis}

Data are expressed as mean \pm S.E.M. One way analysis of variance (ANOVA) followed by Tukey's Test was used to analyze the results with $p<0.05$ considered significant.

\section{Results}

Summaries of cadmium exposure and administration of Cocos nucifera water on the lipid profile of plasma, erythrocytes, 
brain and hepatic compartments of the animals are depicted [Figures 1-4]. Cadmium exposure resulted in a significant $(p<$ 0.05 ) dose - dependent decrease in cholesterol, triacylglyceride and phospholipids concentrations of plasma and erythrocytes

A
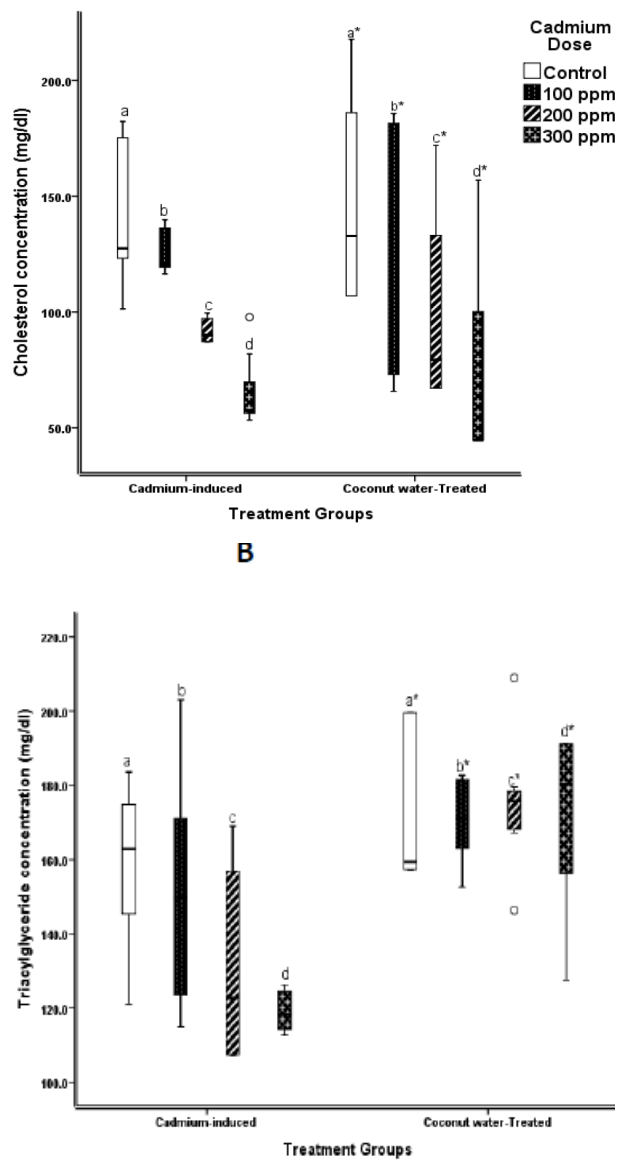

C

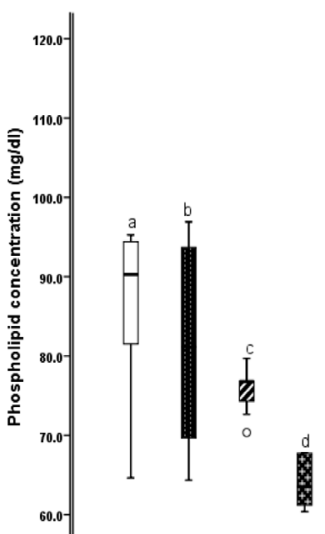

Figure 1: Plasma cholesterol (a), triacylglyceride (b) and phospholipid (c) concentrations of the animals

Bars of the same compartment carrying different letters of the alphabet are significantly different from each other $(p<0.05)$.

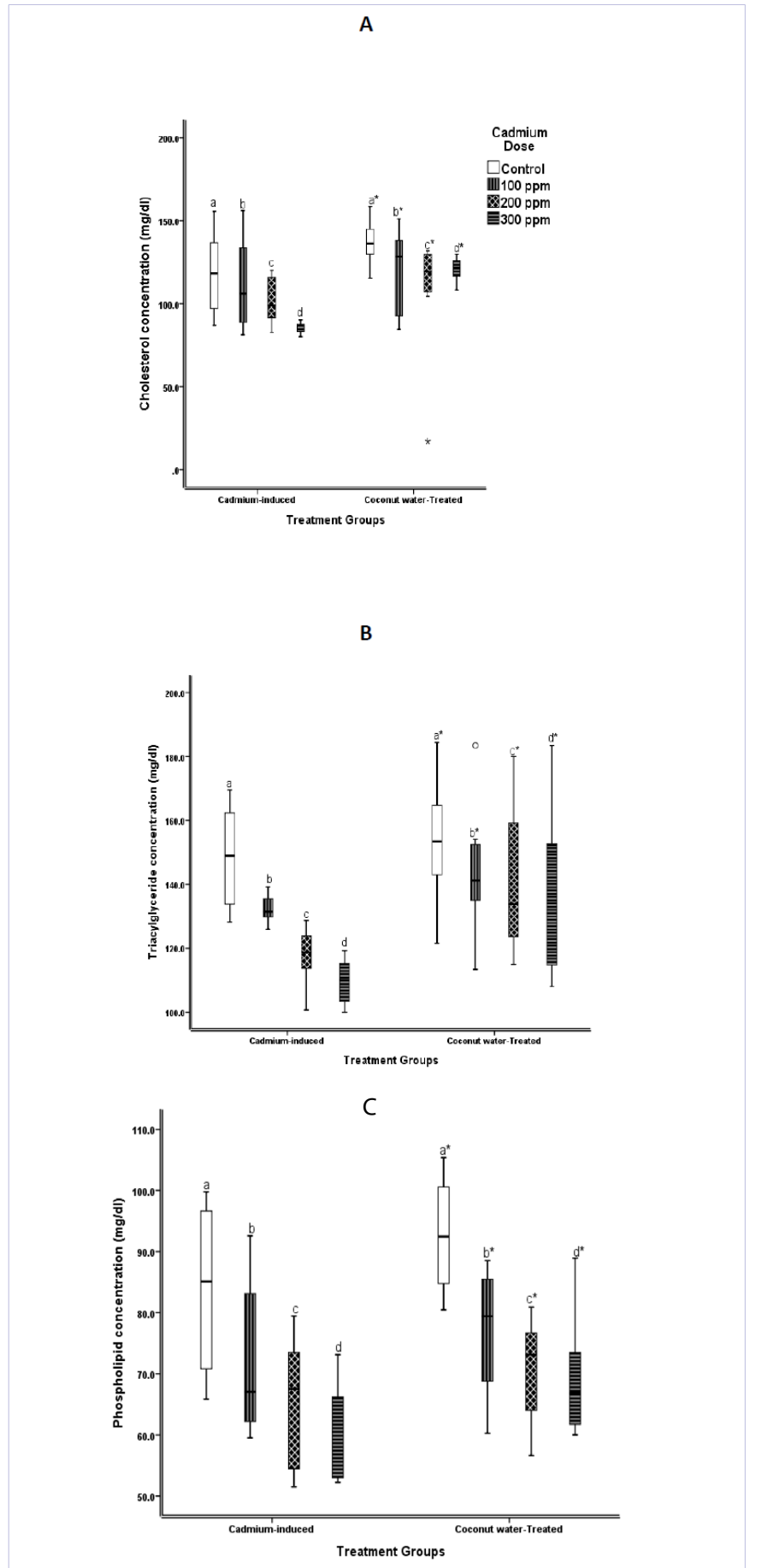

Figure 2: Erythrocyte cholesterol (a), triacylglyceride (b) and phospholipid (c) concentrations of the animals

Bars of the same compartment carrying different letters of the alphabet are significantly different from each other $(p<0.05)$.

[Figures.1 and 2] whereas administration of Cocos nucifera water reversed these effect by 50,1 and $3 \%$ in plasma and 11,12 and $25 \%$ in the erythrocyte compared to control respectively. In the brain [Figure. 3], cadmium exposure resulted in significant $(p<0.05)$ dose-dependent decrease in cholesterol (33\%), triacylglyceride 
(34\%) and increase in phospholipid (25\%) concentrations while the administration of Cocos nucifera water reverses these effects. In fig. 4 the exposure of cadmium resulted in a significant $(p<0.05)$ decrease in cholesterol (35\%), phospholipid $(50 \%)$ contents and $25 \%$ increase in triacylglyceride content. Whereas, administration of Cocos nucifera water lead to decrease in

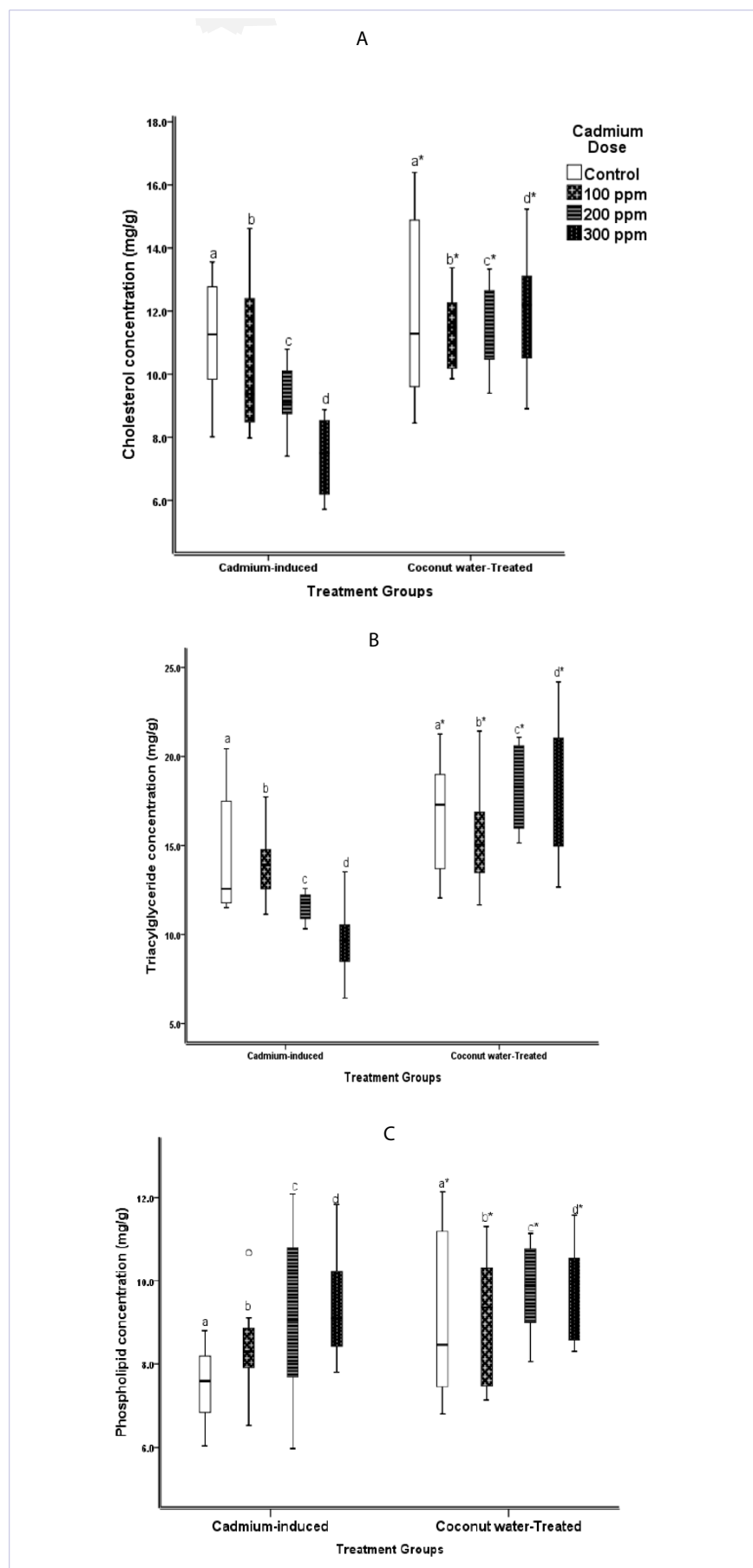

Figure 3: Brain cholesterol (a), triacylglyceride (b) and phospholipid (c) concentrations of the animals

Bars of the same compartment carrying different letters of the alphabet are significantly different from each other $(p<0.05)$.
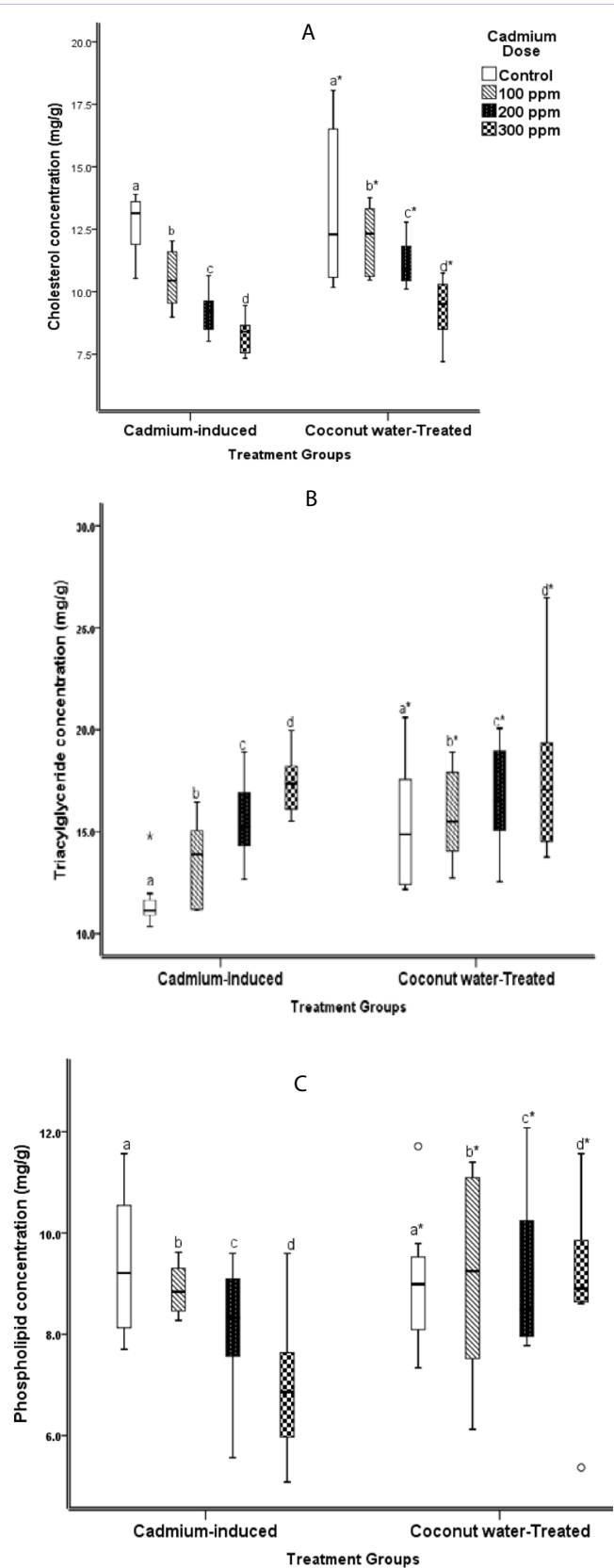

Figure 4: Liver cholesterol (a), triacylglyceride (b) and phospholipid (c) concentrations of the animals

Bars of the same compartment carrying different letters of the alphabet are significantly different from each other $(p<0.05)$.

cholesterol, phospholipid and increase in triacylcglyceride concentration.

\section{Discussion}

Lipids are used for energy storage to form cell membranes, precursors for hormones, have a prominent role as messengers and regulators of inflammation and other cellular functions [21]. Lipid profiles have been shown to be the important predictors for the metabolic disturbances, including dyslipidemia, 
hypertension, diabetes, cardiovascular disease and liver dysfunction [22]. Evidence abounds that cadmium exposure alters the lipid profile $[13,23]$, as observed in this study [Figures 1-4]. The hypolipidemia observed in this study might be due to genetic mutations causing an underproduction or increased clearance of low density lipoproteins by cadmium toxicity and result in lipid levels low enough to cause significant consequences [24]. The defect lipid metabolism might lead to structural and functional central nervous system diseases, by affecting different metabolic pathways such as (1) cholesterol biosynthesis, (2) lipid transport and lipoprotein assembly, (3) receptors that mediate the cellular uptake of lipids, and (4) signaling molecules [25]. The mechanisms underlying the accumulation of liver triacyglycerides include increased liver fatty acid mobilization and delivery to the liver, coupled with increased hepatic lipogenesis and decreased secretion of very low density lipoprotein [26].

The administration of fresh coconut water after induction of Cd showed a significant reversal therapeutic potential on the Cdinduced lipid toxicity. Coconut liquid endosperm called coconut water, with its many applications, is one of the world's most versatile natural products that have multifarious utility. The observed medicinal effect of coconut water may be associated with the presence of bioactive components such as free amino acid L-arginine, vitamins like water-soluble B-vitamins and ascorbic acid, inorganic ions, such as calcium, magnesium and potassium [27, 28]. L-arginine functions as an intermediate in the urea cycle, which takes place mainly in hepatocytes in mitochondria and continues in the cytosol. Different type of metabolic and physiological conditions, triggered by stress may result in partial deficiencies of enzyme production in the urea cycle. These disturbances can be reducing the activity of the enzymes, which disrupts the urea cycle and prevents the body from processing nitrogen effectively. In particular, deficiency of argininosuccinate synthase can trigger the development of dyslipidemia and fatty liver [29] as observed in this study.

The therapeutic explanation could be that the inorganic ions present in the coconut water are required for the normal cellular function and are critical for bone formation, hemoglobin function, gene expression, and enzyme activation of lipid biosynthesis [27, 30-32]. The concentration of inorganic ions known as electrolytes in coconut water generates an osmotic pressure similar to that observed in blood [27]. As a result, coconut water can be used as a short term intravenous hydration fluid under certain emergency situations. Therefore, the basic ion composition of coconut water can replenish the cadmium-induced toxicity, due to the water-soluble B vitamins and minerals which are required as coenzymes for enzymatic reactions essential for cellular function such as prevent mitochondrial toxicity and the transamination and decarboxylation reactions (vitamins B6) [33-35].

Thiamine (Vitamin B1) is a necessary step in the synthesis of fatty acids, steroids, and the aromatic amino acid precursors to a range of neurotransmitters and other bioactive compounds essential for brain function [36], and a cofactor during metabolic processes and contributes to the structure and function of cellular membranes [37]. The flavoproteins (B2) are also co-factors in the metabolism of essential fatty acids in brain lipids [38]. A vast array of processes and enzymes involved in every aspect of peripheral and brain cell function are dependent on vitamin B3 known as niacin and anti-atherogenic lipolysis in adipose tissue [39].

Pantothenic acid (vitamin B5) is a substrate for the synthesis of the ubiquitous coenzyme A which contributes to the structure and function of brain cells via its involvement in the synthesis of cholesterol, amino acids, phospholipids, and fatty acids [40]. In addition to vitamin $B$, coconut water also contains vitamin $C$ (ascorbic acid), which is an important dietary antioxidant [33]. Previous studies showed that coconut water showed the free radical scavenging ability that may be partly attributed to the ascorbic acid [41].

\section{Conclusion}

The present study reveals that fresh matured coconut water has a therapeutic potential on lipid profile in cadmium exposed male rat.

\section{Conflict of Interest}

We declare that there is no conflict of interest.

\section{Acknowledgments}

The authors appreciate the technical staff of the Cell and Tissue Culture Research Laboratory (Drug Discovery Unit); Department of Biochemistry; Lagos State University; Ojo; Lagos; Badagry Expressway; Lagos - Nigeria.

\section{References}

1. Nasiruddin K, Muti UR, Khurram WK. A study of chemical composition of Cocos nucifera L. (Coconut) water and its usefulness as rehydration fluid. Pak. J. Bot. 2003;35(5):925-930.

2. Alleyne T, Roache S, Thomas C, Shirley A. The control of hypertension by use of coconut water and mauby:two tropical food drinks. West Indian Med J. 2005;54(1):3-8.

3. Adam W, Brat DE. Young coconut water for home rehydration in children with mild gastroenteritis. Trop Geogr Med. 1992;44(12):149-53.

4. Campbell-Falck D, Thomas T, Falck TM, Tutuo N, Clem, K. The intravenous use of coconut water. Am J Emerg Med. 2000;18(1):10811.

5. Nnodim J, Dike-Ndudim J, Elendu HN, Nwagbaraocha M, Egbuobi R, Onyeze V. Antioxidant and Cardioprotective Effect of Coconut Water against Doxorubicin Induced Cardiomyopathy. JKIMSU. 2013;2(2):3741.

6. Manisha D, Shyamapada M. Coconut (Cocos nucifera L.: Arecaceae): In health promotion and disease prevention. Asian Pac J Trop Med. 2011;4(3):241-7.doi: 10.1016/S1995-7645(11)60078-3.

7. Satarug S, Moore MR. Adverse health effects of chronic exposure to low-level cadmium in foodstuffs and cigarette smoke. Environ Health Perspect. 2004;112(10):1099-1103.

8. Agency for Toxic Substances and Disease Registry (ATSDR). Toxicological Profile for Cadmium. Atlanta, GA: U.S. Department of Health and Human Services, Public Health Service. 2012. 
9. Jarup L, Berglund M, Elinder CG, Nordberg G, Vahter M (1998) Health effects of cadmium exposure -A review of the literature and a risk estimate. Scand. J. Work Environ. Health. 24(suppl 1):1-51.

10. Asagba SO, Obi FO. A comparative evaluation of the biological effects of environmental cadmium contaminated control diet and laboratory cadmium supplemented test diet. Biometals. 2005;18(2):155-61.

11. Habbeebu S, Liu J, Klaassen CD. Cadmium-induced apoptosis in mouse liver. Toxicol Appl Pharmacol. 1998;149(2):203-9.

12. Sakar S, Yadav P, Bhatnagar D. Lipid peroxidative damage on cadmium exposure and alterations in antioxidant system in rat erythrocytes: A study with relation to time. Biometals. 1998;11(2):153-7.

13. Ogunrinola 00. Lipid Profile and Malondialdehyde Concentrations in Cadmium-Induced Rats: A Study with Relation to Doses. MOJ Toxicol. 2015;1(5). doi: 10.15406/mojt.2015.02.00022.

14. Yaping Liu, Jie Liu, Sultan M. Habeebu, Michael P. Waalkes and Curtis D. Klaassen. Metallothionein-I/II Null Mice Are Sensitive to Chronic Oral Cadmium-Induced Nephrotoxicity. Toxicol Sci. 2000;57(1):167176.

15. Guide for the Care and Use of Laboratory Animals. NIH Publication No. 85-23. Revised 1985.

16. Folch, J, Lees M, Sloane SGH. A simple method for the isolation and purification of total lipids from animal tissues. J Biol Chem. 1957;226(1):497-509.

17. Rose HG, Oklander M. Improved procedure for the extraction of lipids from human erythrocyte. J Lipid Res. 1965;6:428-31.

18. Stewart JCM. Colorimetric determination of phospholipids with ammonium ferrothiocyanate. Anal. Biochem. 1980;104(1):14-16.

19. Allain CC, Poon LS, Clau CSG, Richmond W, Fu PD. Enzymatic determination of total serum cholesterol. Clin. Chem. 1974;20(4):470578.

20. Kriketos AD, Furler SM, Gan SK, Poyten AM, Chisholm DJ, Campbell V. Multiple indexes of lipid availability are independently related to whole body insulin action in healthy humans. J Clin Endocr Met. 2003;88(2):993-998.

21. Watson AD. Thematic review series: Systems biology approaches to metabolic and cardiovascular disorders. Lipidomics: A global approach to lipid analysis in biological systems. J. Lipid Res. 2006;47(10):21012111.

22. Mohammed A, Luka CD. Effect of Coconut Oil, Coconut Water and Palm Kernel Oil on Some Biochemical Parameters in Albino Rats. IOSR J. Pharm Biol Sci. 2013;6(3):56-59.

23. Afolabi OK, Oyewo EB, Adekunle AS, Adedosu OT, Adedeji AL. Impaired lipid levels and inflammatory response in rats exposed to cadmium. EXCLI Journal. 2012;11:677-687.

24. Elmehdawi RR. Hypolipidemia: A Word of Caution. Libyan J Med. 2008; 3(2): 84-90. doi: 10.4176/071221.

25. Herz J. Apolipoprotein E receptors in the nervous system. Curr Opin Lipidol. 2009;20(3):190-6. doi: 10.1097/MOL.0b013e32832d3a10.
26. Elizabeth PN, Susan MK, Yan Xie, Jianyang L, Susan ES, Clay FS, et al. Altered hepatic triglyceride content after partial hepatectomy without impaired liver regeneration in multiple murine genetic models. Hepatology. 2008;48(4):1097-105. doi: 10.1002/hep.22473.

27. Jean WH, Yong LG, Yan FN, Swee NT. The Chemical Composition and Biological Properties of Coconut (Cocos nucifera L.) Water. Molecules. 2009;14(12):5144-64. doi: 10.3390/molecules14125144.

28. Reddy EP, Lakshmi T. Coconut Water - Properties, Uses, Nutritional Benefits in Health and Wealth and in Health and Disease: A Review. J. Curr. Trends in Clin. Med. Lab Biochem. 2014;2(2):1-13.

29. Komatsu M, Yazaki M, Tanaka N, Sano K, Hashimoto E, Takei Y, et al. Citrin deficiency as a cause of chronic liver disorder mimicking non-alcoholic fatty liver disease. J Hepatol. 2008;49(5):810-20. doi: 10.1016/j.jhep.2008.05.016.

30. Institute of Medicine (IOM), (2000) Dietary Reference Intakes for Calcium, Phosphorus, Magnesium, Vitamin D, and Fluoride. National Academy Press: Washington, DC, USA.

31. Institute of Medicine (IOM). Dietary Reference Intakes for Vitamin C, Vitamin E, Selenium, and Carotenoids; National Academy Press: Washington, DC, USA(2000).

32. Institute of Medicine (IOM). Dietary Reference Intakes for Vitamin A, Vitamin K, Arsenic, Boron, Chromium, Copper, Iodine, Iron, Manganese, Molybdenum, Nickel, Silicon, Vanadium, and Zinc; National Academy Press: Washington, DC, USA(2001).

33. Depeint F, Bruce WR, Shangari N, Mehta R, O'Brien PJ. Mitochondrial function and toxicity: Role of $B$ vitamins on the one-carbon transfer pathways. Chem Biol Interact. 2006;163(1-2):113-32.

34.Garrett RH, Grisham GM (2005) Biochemistry, 3rd ed.; Thomson Brooks/Cole: Belmont, CA, USA.

35. Shenkin A. The key role of micronutrients. Clin Nutr. 2006 Feb;25(1):113.

36. Kerns IC, Arundel C, Chawla LS. Thiamin deficiency in people with obesity. Adv Nutr. 2015;6(2):147-53. doi: 10.3945/an.114.007526.

37. David OK. B Vitamins and the Brain: Mechanisms, Dose and Efficacy-A eview. Nutrients. 2016;8(2):68. doi: 10.3390/nu8020068.

38. Sinigaglia-Coimbra R, Lopes AC, Coimbra CG. Riboflavin deficiency, brain function, and health. In Handbook of Behavior, Food and Nutrition; Springer: Berlin, Germany. 2011:2427-2449.

39. Zhang Y, Schmidt RJ, Foxworthy P, Emkey R, Oler JK, Large TH. Niacin mediates lipolysis in adipose tissue through its g-protein coupled receptor HM74A. Biochem. Biophys. Res. Commun. 2005;334(2):729732. doi: 10.1016/j.bbrc.2005.06.141.

40. Rucker RB, Bauerly K. Pantothenic acid. In Handbook of Vitamins, 5th ed.; Zempleni, J., Suttie, J.W., Gregory, J.F., III, Stover, P.J., Eds.; CRC Press: Boca Raton, FL, USA (2013).

41.Loki AL, Rajamohan T. Hepatoprotective and Antioxidant Effect of Tender Coconut Water on Carbon Tetrachloride Induced Liver Injury in Rats. Indian J Biochem Biophys. 2003;40(5):354-7. 